\title{
INTERPRETAÇÃO DE FONTES PATRIMONIAIS EM EDUCAÇÃO HISTÓRICA
}

\section{INTERPRETATION OF HERITAGE SOURCES IN HISTORY EDUCATION}

\author{
Helena Pinto ${ }^{1}$
}

\begin{abstract}
RESUMO: Relacionando Educação Histórica e Educação Patrimonial, pretende-se desenvolver de forma sistemática e segundo critérios metodológicos, atividades educativas relacionadas com o uso de objetos e sítios históricos. Num estudo empírico descritivo e numa abordagem essencialmente qualitativa, pretendeu-se investigar de que forma os alunos inferem, com base em fontes patrimoniais, em atividades de ensino e aprendizagem de História realizadas no exterior da escola. Os dados aqui apresentados reportam-se ao estudo principal de investigação, no qual instrumentos específicos foram aplicados a uma amostra de 87 alunos (40 alunos do 70 ano e 47 do $10^{\circ}$ ano de escolaridade) de cinco escolas do município de Guimarães, no norte de Portugal, e aos respectivos professores de História. Os dados foram analisados mediante um processo de categorização progressivamente refinado no sentido de encontrar modelos de progressão conceptual relativos a alunos e perfis de professores sobre o uso de fontes patrimoniais e tipos de consciência histórica. O estudo salienta o interesse do uso de fontes patrimoniais no ensino e aprendizagem de História, como evidência histórica e não apenas como ilustração ou informação.
\end{abstract}

Palavras-chave: Educação Histórica. Educação Patrimonial. Fontes patrimoniais. Evidência histórica.

ABSTRACT: Connecting History Education and Heritage Education, this research aim to develop educational activities related to use of objects and heritage sites, grounded in a systematic process and methodological criteria. Through a descriptive empirical study and a mainly qualitative approach, it was intended to seek out how students infer from heritage sources, taking part in history teaching and learning activities. Data here reported refer to a PhD study in which specific instruments were applied to a sample of 87 students (40 students attending year 7 and 47 students from year 10), from several secondary schools of Guimarães municipality, in northern Portugal, and their history teachers. The analysis of data followed an increasingly refined categorization process in order to find out a model of students' conceptual progression and of teachers' profiles concerning the use of heritage sources and types of historical consciousness. This study highlights the interest of approaching heritage sources as historical evidence, and not only as illustration or information, in history teaching and learning activities.

Keywords: History Education. Heritage Education. Heritage sources. Historical evidence.

${ }^{1}$ Doutora em Ciências da Educação - especialidade de Educação em História e Ciências Sociais; investigadora externa do CIEd, Universidade do Minho. 


\section{Introdução}

Com base numa reflexão sobre abordagens de Educação Histórica e de Educação Patrimonial que integrou uma investigação de doutoramento em Ciências da Educação realizada na Universidade do Minho (Portugal) e o Projeto HiCon [Consciência histórica - teoria e práticas II], apoiado pela Fundação para a Ciência e a Tecnologia, em Portugal, procurou-se contribuir para a pesquisa sobre consciência histórica integrando uma perspectiva de evidência patrimonial, inspirada na reflexão filosófica de Jörn Rüsen (2001a,b, 2004) e Peter Lee $(2002,2003,2005)$ na área de investigação em Educação Histórica.

Salienta-se o interesse do uso de fontes patrimoniais no ensino e aprendizagem de História, como já se apresentou nas Jornadas Internacionais de Educação Histórica (PINTO, 2011a; PINTO; BARCA, 2011, PINTO; BARCA, 2012), nomeadamente que os professores podem desempenhar um papel fundamental para que os alunos deem sentido ao património como evidência histórica, e não apenas como simples ilustração ou informação.

\section{Consciência patrimonial e consciência histórica}

A característica que mais sobressai da reflexão sobre o conceito de património é a da temporalidade: se a essência dos objetos patrimoniais diz respeito ao passado, é nos tempos modernos que ela se manifesta e legitima (YÁNEZ CASAL, 1999). Por isso, Choay afirma que, para interpretarmos as imagens que o "espelho do património" nos reenvia, devemos, antes de mais, "compreender como a grande superfície desse espelho foi constituída, pouco a pouco, pela soma e fusão de fragmentos, a princípio chamados antiguidades e, depois, monumentos históricos" (CHOAY, 2000, p. 24). O património tem, portanto, uma história. A apresentação do património variou segundo o ideário de cada época, os seus valores e signos culturais, permitindo esclarecer sobre o modo como 
as sociedades assumiram a sua relação com a temporalidade e construíram as suas identidades.

Nos últimos anos temos assistido a um crescente interesse pela identificação, preservação e divulgação do património. Este interesse, centrado inicialmente nos monumentos de maior significado histórico, alargou-se posteriormente aos centros históricos e, mais recentemente, a abordagens ambientalistas e ecologistas, tentando contrariar as agressões provocadas pelas mudanças urbanísticas e pelas massivas alterações das paisagens. Com ritmos diversos, mas constantemente, as características culturais de todas as sociedades mudam, e as mudanças conduzem fatalmente ao desaparecimento de certos elementos até aí familiares: pessoas, comportamentos, diversos saber-fazer, paisagens construídas ou naturais. É nesses momentos que se poderá produzir a tomada de consciência patrimonial.

A consciência do impacto contínuo da humanidade sobre os vestígios do passado intensificou-se durante o século $X X$ : muitos edifícios $e$ artefactos foram, ao longo dos tempos, adaptados a novos usos, mas o impulso pela preservação tornou essa adaptação mais consciente. Lowenthal considera que conhecemos o passado porque lembramos coisas, lemos ou ouvimos histórias e vivemos entre vestígios de tempos anteriores. Os vestígios tangíveis constituem, por isso, "pontes essenciais entre o passado e o presente", pois simbolizam "laços coletivos ao longo do tempo, e oferecem metáforas arqueológicas que iluminam os processos da História e da memória" (LOWENTHAL, 1999, p. xxiii). Cada ação retém conteúdo residual de outros tempos, mas não podemos evitar refazer o passado, pois "só alterando e acrescentando àquilo que se preserva, se poderá manter real, vivo e compreensível o nosso património" (LOWENTHAL, 1999, p. 411). Quando tomarmos consciência de que o passado e o presente não são exclusivos, deixaremos de insistir na preservação de um passado fixo e estável.

Os critérios para a tomada de decisões sobre o que é mais importante e vale a pena preservar, ou que aspetos do passado de uma comunidade são sinais da sua singularidade, conheceram alterações com o tempo. A 
ligação a um acontecimento histórico importante ou a qualidade do monumento foram, de início, critérios essenciais de preservação; os critérios científicos arqueológicos e os motivos económicos de promoção turística surgiram mais tarde; e ainda mais recentemente, passou-se a reconhecer que a preservação tem um cunho moral e que "os ambientes ricos em tais características são lugares mais agradáveis onde viver" (LYNCH, 1998, p. 30). Defende-se, geralmente, aquilo que se conhece ou o que se valoriza, mas estes dois aspetos nem sempre estão ligados. A valorização pode resultar da natureza simbólica atribuída pela comunidade a um património cuja conservação é garantia de continuidade entre o passado e o futuro.

Tal como o património, a consciência histórica é uma construção simbólica e, do mesmo modo que a identidade, comporta um processo de apropriação simbólica do real. A consciência histórica inclui as operações mentais - emocionais e cognitivas, conscientes e inconscientes - através das quais o tempo, experienciado em forma de memória, é usado como meio de orientação na vida prática (RÜSEN, 2001b). Desta forma, a consciência histórica não reduz o tempo com significado apenas ao passado, mas excede as suas dimensões; o passado humano recordado pela consciência histórica é um processo temporal que se refere também ao presente e ao futuro. A História, como conteúdo da consciência histórica, é uma relação entre presente e futuro, surgindo com e no passado recordado (RÜSEN, 2001b). Esta relação entre passado, presente e futuro não é puramente material ou objetivamente factual, pois envolve também 0 subjetivo, vertente não-material da consciência humana.

Segundo Rüsen (2001b), a consciência histórica é também estimulada e influenciada pelas experiências do presente, pelo que a sua função de atribuir significado está, em larga medida, dependente do contexto onde é produzida. Parte do presente para o passado e regressa ao presente com experiências para revelar o futuro como referência de ação. Na sua orientação temporal, a consciência histórica do sujeito liga o passado ao presente de forma a conferir à realidade presente uma perspetiva futura. Esta referência ao futuro está implícita na interpretação histórica do 
presente porque tais interpretações devem permitir-nos agir, ou seja, devem facilitar a direção das nossas intenções numa matriz temporal, uma conceção do curso do tempo fluindo pelas vicissitudes da vida quotidiana, guiando o curso da ação.

Mas, como lembra Barca (2008), se a consciência histórica constitui uma atitude de orientação temporal sustentada pelo conhecimento da História, distingue-se de uma simples resposta de senso comum às exigências práticas em termos de sentimentos de identidade, onde adquire contornos de identidade nacional, ou de identidade local, ou até de simples sentido de pertença a um determinado grupo. Nesta diferença reside parte da distinção entre consciência histórica e memória coletiva.

A aprendizagem é, segundo Rüsen (2004) uma qualidade específica dos procedimentos mentais da consciência histórica. A aprendizagem histórica envolve mais do que a simples aquisição de conhecimentos do passado e o aumento desse conhecimento. Vista como um processo em que se adquirem progressivamente competências, emerge como um "processo de mudança das formas estruturais através das quais utilizamos e lidamos com a experiência e o conhecimento da realidade passada, progredindo de formas tradicionais de pensamento para as ontogenéticas" (RÜSEN, 2004, p. 81). A aprendizagem de História modifica-se à medida que o conteúdo da consciência histórica é reconhecido como produto da atividade mental, perdendo o cariz recetivo inicial e assumindo qualidades produtivas. Desta forma, a consciência histórica torna-se uma das categorias chave da 'didática' da História (RÜSEN, 2001b).

Neste âmbito, a teoria de Rüsen, nomeadamente a sua tipologia vista em termos de significação temporal - diversas formas de dar sentido ao passado, de compreender a relação entre passado, presente e futuro, e de construção de identidades históricas - e o seu conceito de memória histórica, contribuíram para informar esta investigação que decorreu num contexto específico: atividades de educação histórica e patrimonial (com alunos e professores) durante um percurso num sítio histórico, Guimarães. Na verdade, no centro histórico de Guimarães, além do Castelo e de outros monumentos, há um vasto e diversificado património que ultrapassa a 
dimensão histórico-arquitetónica, e cuja preservação e enquadramento no tecido urbano e social é importante assegurar. A classificação como Património Cultural da Humanidade, em 2001, associou-Ihe uma dimensão universalizante, mas pretender simbolizar uma cultura que se universaliza a partir de fragmentos patrimoniais específicos, pode descurar modos de vida e expressões culturais locais cuja historicidade, interpretada de forma apropriada, poderá ser um contributo para a compreensão do passado percecionado através dos seus vestígios e do presente vivido.

\section{Utilização de fontes patrimoniais em educação histórica}

Collingwood $(1946,2001)$ já havia descrito a História construtiva como consistindo na interpretação, entre as afirmações feitas pelas fontes, de outras afirmações deduzidas daquelas, considerando que "a interpolação não é, de modo algum, arbitrária ou meramente imaginativa" (COLLINGWOOD, 2001, p. 252). Afirmava que a imaginação é indispensável para percebermos o mundo à nossa volta e, por isso, também o é para a História: a imaginação histórica difere da "imaginação pura ou livre do artista" e da "imaginação percetiva", não por ser apriorística, mas por ter como tarefa especial imaginar o passado: "não um objeto de possível perceção, uma vez que já não existe, mas suscetível de se tornar, através da imaginação histórica, um objeto do nosso pensamento." (COLLINGWOOD, 2001, p. 253). Assim, para este autor, o pensamento histórico é a atividade da imaginação, utilizando o presente como evidência do seu passado.

Também McCullagh (1998) sublinha que a evidência é precisamente o que dá acesso ao passado. Para os historiadores, os critérios para determinar o grau de aceitabilidade de uma versão assentam, normalmente, em princípios de consistência evidencial e lógica. Dado que o passado é inacessível à observação presente, os historiadores têm que fazer inferência, a partir das fontes, acerca das ações das pessoas e situações do passado. 
Convém assinalar que, até ao momento em que colocamos questões acerca dos vestígios do passado, estes não são ainda evidência. Já Collingwood (2001) afirmara que as questões e as evidências são correlativas. Cooper (2007) lembra que o processo de pesquisa histórica foi clarificado por Collingwood na sua autobiografia, publicada em 1939, onde o autor partiu de "questões específicas sobre as fontes, para o significado e função que os objetos, quer fossem botões, habitações ou acampamentos, teriam para as pessoas que os produziram e usaram" (COOPER, 2007, p. 6). A sequência procedia do que podia ser conhecido acerca do objeto, para o que se podia supor e, por fim, o que se gostaria de saber de modo a suportar, alargar ou contradizer as suposições. Collingwood identificou questões chave: "Como foi feito? Porquê? Como era usado? Por quem? Havia outros? O que significava para a pessoa que o fez e usou?" (COOPER, 2007, p. 9). Muitas das ideias defendidas por Collingwood, nomeadamente acerca da relação das questões com a prática histórica, e não apenas com significado literal, tiveram reflexo em estudos posteriores acerca da progressão do pensamento dos alunos em História.

Dickinson, Gard e Lee afirmam que, sem questões, não pode existir evidência: "são elas que transformam meros vestígios em evidência do passado" (DICKINSON; GARD; LEE, 1978, p. 5). São as questões que os historiadores colocam e a forma como lhes respondem, que distinguem a História como disciplina. Por sua vez, Ashby (2006) alerta que se é a natureza das questões sobre o passado que determina o que conta como evidência histórica na validação de qualquer afirmação, diferentes questões estão relacionadas de diferentes formas com a evidência, pelo que essa relação determina também diferentes estatutos das afirmações feitas. No entanto, Ashby lembra que, após três décadas de "trabalho crítico com fontes", as pesquisas no Reino Unido sugerem que muitos alunos continuam a mostrar uma "forte propensão para tratar a informação tal como ela é dada e fazer apelo às autoridades, embora reconheçam que o nosso conhecimento do passado resulta de vestígios materiais" (ASHBY, 2006, p. 153) que permaneceram. 
O estudo de Cooper (2004) revelou que o uso de estratégias de ensino que envolvam experiências com significado (como as visitas a sítios e museus onde as crianças possam explorar e extrapolar), questões abertas sobre evidência (de modo a permitir diferenciarem entre 'saber', 'supor' e 'não saber'), vocabulário selecionado com diferentes níveis de abstração, e uma atmosfera de expressão livre, onde as crianças possam sentir-se confiantes para conversar, são fundamentais para o desenvolvimento do pensamento histórico das crianças. Cooper salienta que este trabalho deve começar desde cedo, poisas crianças são "capazes de operar com conceitos de validade e de resolver questões históricas progressivamente mais complexas, podendo aprender conceitos históricos abstratos interligando-os com os concretos" (COOPER, 2004, p. 60), pelo que não devem ser restringidas à repetição de informação. Também Chapman (2006) salienta que os alunos acostumados a pensar em termos hipotéticos podem conseguir melhor desempenho quando confrontados com argumentos e interpretações históricos. Sugere a realização de tarefas relacionadas com descobertas arqueológicas nas quais os jovens sejam levados a selecionar informação, a apontar conclusões baseadas nos 'factos', a identificar as conjeturas realizadas e a discuti-las em grupo. Desta forma pode-se ajudar os alunos a reconhecer que há inferências que dependem de conjeturas mas não são suportadas pela evidência, enquanto outras inferências se baseiam em suposições válidas.

Nakou (2006) considera a abordagem, leitura e interpretação da cultura material, nomeadamente os objetos dos museus, como procedimentos fundamentais da educação em geral, e da educação histórica em particular, permitindo aos alunos a ligação à materialidade do presente e às realidades do passado. $E$ os benefícios educativos dessas ações parecem estar mais relacionados com a natureza dos métodos usados do que com o tipo de museus visitado. Nesse sentido, Nakou (2003) já salientara que os objetos dos museus levam os alunos a tentarem descodificar o seu significado, o que apela à sua imaginação histórica, permitindo ainda reconhecer que o passado não pode ser conhecido diretamente. Criam-se condições para o avanço na compreensão da 
evidência, dado que os alunos ao estudarem o passado a partir dos objetos do museu, guiados por questões apropriadas, podem desenvolver mais facilmente o seu pensamento histórico.

Já em 1980, Shemilt entendia que mediante o trabalho de campo sobre um dado tópico se pode promover o interesse e o conhecimento dos vestígios visíveis do passado, apoiando também os alunos na prática de lidar com fontes de vários tipos, relacionando-as, reconstruindo a vida diária e os materiais, e explicando a mudança. Por sua vez, com um trabalho mais aprofundado seria possível reforçar a compreensão dos alunos sobre a natureza da investigação histórica requerendo a empatia acerca das ideias e motivos dos seus antecessores, e "a reconstrução de quadros de referência nos quais essas ideias e motivos possam ser vistos como racionais e justificáveis" (SHEMILT, 1980, p. 5). Concentrando a atenção em ideias e crenças, valores e atitudes de pessoas de diferentes tempos e lugares, surgem questões acerca do uso e interpretação de fontes e do significado das ações humanas.

Estabelecendo uma relação entre o museu e o ensino de História, Ramos (2004) lembra que, no quotidiano, usamos uma infinidade de objetos mas raramente pensamos sobre eles, o que limita também a reflexão sobre os objetos dos museus. Por isso, defende a realização de atividades vinculadas à 'historicidade dos objetos' na própria sala de aula, para que o professor motive a perceção dos alunos a partir de materiais do quotidiano, abrindo espaço para a perceção mais ampla diante da exposição museológica. Salienta, ainda, que os objetos, expostos no museu ou na cidade, podem tornar-se fontes de educação patrimonial e, nesse sentido, a aprendizagem da História não deve ser realizada somente na sala de aula, pois a "pedagogia do objeto" (RAMOS, 2004, p. 48) pode usar-se em muitos outros territórios.

Em Portugal, a Lei de Bases do Sistema Educativo (Lei n.o 46/86, de 14 de outubro), alude, no artigo 3, ao papel da educação na defesa do património, através da "consciencialização relativamente ao património cultural do povo português, no quadro da tradição universalista europeia e da crescente interdependência e necessária solidariedade entre todos os 
povos do Mundo". Ao nível de educação formal, está presente, como se constata neste excerto, a associação do património cultural às ideias de identidades (sobretudo nacional, mas não exclusivista) e de consciência histórica e patrimonial. Esta mensagem tem em si implícita a possibilidade de uma pluralidade de enfoques da temática do património cultural ao nível das áreas curriculares dos diversos graus de ensino.

Um estudo realizado no âmbito do projeto europeu Youth and History (ANGVIK; BORRIES, 1997) procurou investigar os mecanismos individuais e sociais de interiorização do passado histórico pelos jovens, ou seja, a sua "consciência histórica", revelou que os jovens portugueses foram os que mais se manifestaram a favor dos museus e lugares históricos como fontes privilegiadas para a aprendizagem da História. Todavia, as aprendizagens mais recorrentes nas suas aulas concentraram-se em duas dimensões: a factual - "procuramos conhecer os principais factos da História" - e a regionalista/patrimonial - "aprendemos a valorizar a preservação das ruínas históricas e das construções antigas" e "aprendemos a reconhecer as tradições, características, valores e tarefas da nação e da sociedade" (PAIS, 1999, p. 54). Os resultados desta investigação permitiram o alargamento do campo de ação da educação histórica, pois reforçaram a necessidade de se pensar e analisar os conhecimentos históricos num contexto social que extravasa o escolar e as articulações que se estabelecem entre este e o saber académico. Isto implica que se compreenda a educação histórica como um processo que não pode ser encarado simplesmente dentro da redoma da sala de aula: os desafios e as potencialidades do ensino e da aprendizagem não estão restritos à relação professor-aluno na sala de aula, mas envolvem o meio em que vivem, os conhecimentos e pontos de vista veiculados pelas suas famílias, pelas instituições que frequentam e pelos meios de comunicação a que acedem.

Relativamente aos tipos de consciência histórica revelados por alunos em situação de interpretação de fontes patrimoniais, Seixas e Clark (2004) apresentaram os resultados de uma investigação realizada no Canadá, tendo analisado 57 respostas de alunos a uma tarefa em que se pedia que decidissem o que fariam com um conjunto de murais das décadas de 1920- 
30 relativos ao período colonial. Os investigadores categorizaram as respostas dos alunos em quatro tipos: monumental, acreditam que os monumentos são construídos para representar os fundadores, os heróis da nação, de forma a durarem indefinidamente, e se não celebram heróis individuais, marcam vitórias ou acontecimentos chave do passado nacional, identificando-se assim com a trajetória da memória coletiva, a fundação e o progresso da nação; antiquário, consideram que o património deve ser preservado para garantir continuidade com o passado e identidade com 0 coletivo, invocando uma dívida para com os seus antepassados que se sacrificaram, mostrando respeito pelo passado independentemente da perspetiva sobre o que se observa; crítico, considera que os sítios e símbolos de um passado 'negativo' devem ser eliminados de forma a criar uma ordem mais perfeita, a uma sociedade mais justa; moderno, propõe o estudo dos monumentos e memoriais como produtos do seu tempo, historicizando-os, estabelecendo uma conexão com o passado, não de continuidade, mas compreendendo a mudança a partir do um momento histórico concreto, o presente, e conceptualizando os valores em termos de pluralismo de pontos de vista. As respostas destes alunos integraram maioritariamente o tipo crítico, em menor número os tipos antiquário e moderno, e nenhuma o tipo monumental.

A abordagem de assuntos da história local pode levar os alunos a refletirem sobre evidência histórica e patrimonial, a questionarem, a ouvirem diferentes argumentos, a justificarem decisões. Como salientam Ashby, Lee e Shemilt (2005), os alunos chegam à sala de aula com ideias prévias, mas a relação entre essas ideias prévias a analisar e os conhecimentos de conceitos-chave a ensinar é essencial para assegurar que se verifica a progressão dos conhecimentos dos alunos. Alguns elementos chave do pensamento histórico, tais como os conceitos de tempo, de mudança, ou fazer inferências a partir das fontes, podem ser desenvolvidos de formas mais sofisticadas com o avançar da idade das crianças, como salienta Cooper (2006). Mas lembra, também, que elas já conhecem informações acerca do passado mesmo antes de iniciarem a sua educação 
formal, devendo, por isso, ser tidas em conta nas experiências educativas que lhes são dirigidas.

Os currículos tradicionais concentravam-se excessivamente na apresentação da herança nacional aos alunos e tratavam a História como um corpo de informação recebida para ser aceite e memorizada; as "fontes primárias" eram apenas usadas ocasionalmente para estimular a curiosidade, o interesse, e mesmo admiração, ou para ilustrar casos particulares. Contudo, em Portugal ainda se verifica, quer nos programas da disciplina de História, quer na prática de sala de aula, um enfoque em fontes escritas e, por vezes, iconográficas. A utilização de fontes patrimoniais no ensino de História, nomeadamente em contexto, não é tão frequente como seria desejável, como mostraram diversos estudos de Educação Histórica. Para que isso se faça de forma consistente, é necessário promover uma educação patrimonial a um nível fundamentado: proporcionar recursos e atividades desafiadoras, usar fontes patrimoniais de forma a contribuir para o desenvolvimento da compreensão dos conceitos históricos pelos alunos e a interpretação dos contributos culturais, sociais e económicos de diversos grupos nas suas comunidades.

A educação histórica pode assumir um papel essencial na educação patrimonial, uma vez que os objetos de museus e sítios históricos, quando explorados com tarefas cuidadosamente planeadas e que estimulem a interpretação histórica, podem proporcionar a compreensão da evidência que dá sentido ao passado, como mostram os estudos de Ashby (2003), Cooper (2004), Cainelli (2006), Levstik, Henderson e Schlarb (2005), Nakou (2003), Pinto (2009, 2011a, 2011b), Pinto; Barca (2011) Schmidt e Garcia (2007), Simão (2007), Solé (2009), entre outros. E, perante a impossibilidade, pelo menos no contexto atual, da integração da educação patrimonial como corpo disciplinar autónomo no currículo, parece ser fundamental o papel da disciplina de História na sua implementação e aplicação em atividades escolares, nomeadamente no 30 ciclo do ensino básico e no ensino secundário (enquanto enfoque deste estudo) em Portugal. 
Dada a transversalidade que caracteriza a educação patrimonial, e que resulta da heterogeneidade inerente ao património (desde o material ao intangível, do cultural ao natural, do imóvel ao móvel...), parece de toda a pertinência a abordagem de fontes patrimoniais na disciplina de História e a investigação dessas atividades no âmbito da Educação Histórica. Se é verdade que os extensos programas da disciplina de História não disponibilizam muito tempo para o detalhe, para a discussão e a argumentação refletida, também é possível, através da seleção de assuntos que poderão ser tratados no âmbito da história local, introduzir de forma interessante e adequada ao currículo a abordagem da educação patrimonial no âmbito da disciplina de História, recorrendo, por exemplo, a um museu local ou a sítios históricos próximos da escola.

\section{Interpretação de fontes patrimoniais: método do estudo}

Baseando-se nos dados recentes da cognição histórica, a pesquisa em educação histórica, que é sobretudo de índole qualitativa, tem-se focalizado não só em ideias substantivas necessárias à construção de um quadro sobre o passado, como também em ideias sobre a natureza da História, como a de evidência. Os conhecimentos fornecidos pela investigação sobre as ideias dos alunos, em diversos países, têm revelado que crianças e adolescentes em vários níveis de escolaridade, operam com argumentos mais ou menos sofisticados em relação à natureza da História.

Neste âmbito, o estudo de investigação que desenvolvemos teve como principal enfoque a articulação entre a evidência e a consciência históricas no que respeita a concepções de alunos e de professores, com especial atenção para o uso de fontes patrimoniais no ensino e aprendizagem de História, dada a sua relação com o processo de construção de significado acerca do passado.

A reflexão sobre o problema inicial deste estudo - De que forma alunos e professores de História interpretam a evidência de um sítio 
histórico? - revelou a necessidade de se responder às seguintes questões de investigação, relativas a conceções de alunos e de professores:

- Como usam os alunos de 70 e de $10^{\circ}$ anos de escolaridade os sítios históricos - espaços, edifícios e objetos com eles relacionados enquanto evidência de um passado em mudança?

- Que tipo de pensamento histórico desenvolvem os alunos em ambiente de exploração direta do património?

- Que conceções acerca da exploração do património revelam os professores em contexto de atividades relacionadas com o uso de fontes patrimoniais, no âmbito do currículo escolar?

O estudo, que assumiu uma abordagem metodológica essencialmente qualitativa, fundada na Grounded Theory (STRAUSS; CORBIN, 1998), procurou aprofundar, numa perspetiva transversal em termos de anos de escolaridade, a compreensão dos sentidos atribuídos por alunos e professores de História a fontes patrimoniais. Apresentando uma proposta relacionada com a educação histórica e patrimonial, o estudo desenvolveuse em três fases: exploratória, piloto (em quatro etapas) e principal. No estudo principal, participaram 87 alunos $^{2}$ (40 de 70 ano e 47 de $10^{\circ}$ ano a frequentar a disciplina de História A ou História da Cultura e das Artes) de 5 escolas da cidade de Guimarães, no norte de Portugal, e ainda 6 professores das 7 turmas participantes. Os instrumentos consistiram num 'guião-questionário' para os alunos - propondo um conjunto de tarefas escritas a realizar em vários pontos de paragem de um percurso, em situação de observação direta e de interpretação de um conjunto de fontes patrimoniais (objetos, edifícios, locais históricos) relacionadas com a Idade Média, mas tendo em conta a sua historicidade - e dois breves questionários para os professores (um prévio à atividade e outro posterior), tendo como objetivo a resposta à terceira questão de investigação. Realizaram-se, ainda, entrevistas de seguimento a 33 alunos no sentido da clarificação de algumas respostas escritas.

\footnotetext{
${ }^{2}$ A amostra participante no estudo principal distribuiu-se, no 70 ano de escolaridade, entre os 12 e os 14 anos de idade, sendo o grupo maioritário o de 12 anos; no $10^{\circ}$ ano de escolaridade, distribuíam-se entre os 15 e os $18+$ anos de idade, sendo o grupo maioritário o de 15 anos de idade.
} 
O guião-questionário, com tarefas escritas a realizar pelos alunos colocando questões que fossem acessíveis e desafiadoras para ambos os grupos do 70 ano e do $10^{\circ}$ ano de escolaridade - estruturou-se tendo em atenção um percurso por alguns locais do centro histórico de Guimarães e zona envolvente. Procurou-se eleger um contexto histórico que pudesse ser significativo a nível local e nacional (e também internacional), permitindo o seu enquadramento curricular, e delinear uma abordagem de educação histórica e patrimonial que constituísse um desafio cognitivo genuíno para os alunos. Isto permitiria aos alunos terem uma ideia de conjunto, e não de objetos isolados, fragmentados ou descontextualizados, mesmo quando já não se encontram no espaço original, como acontece com os objetos observados no Museu de Alberto Sampaio, situado no centro histórico de Guimarães. Daí ter-se integrado, também, na introdução do "guiãoquestionário", duas figuras representando plantas - uma da antiga 'vila de Guimarães' e outra da cidade atual (Figura 1) - onde é assinalada a área a percorrer, que os alunos observam antes e durante o percurso.

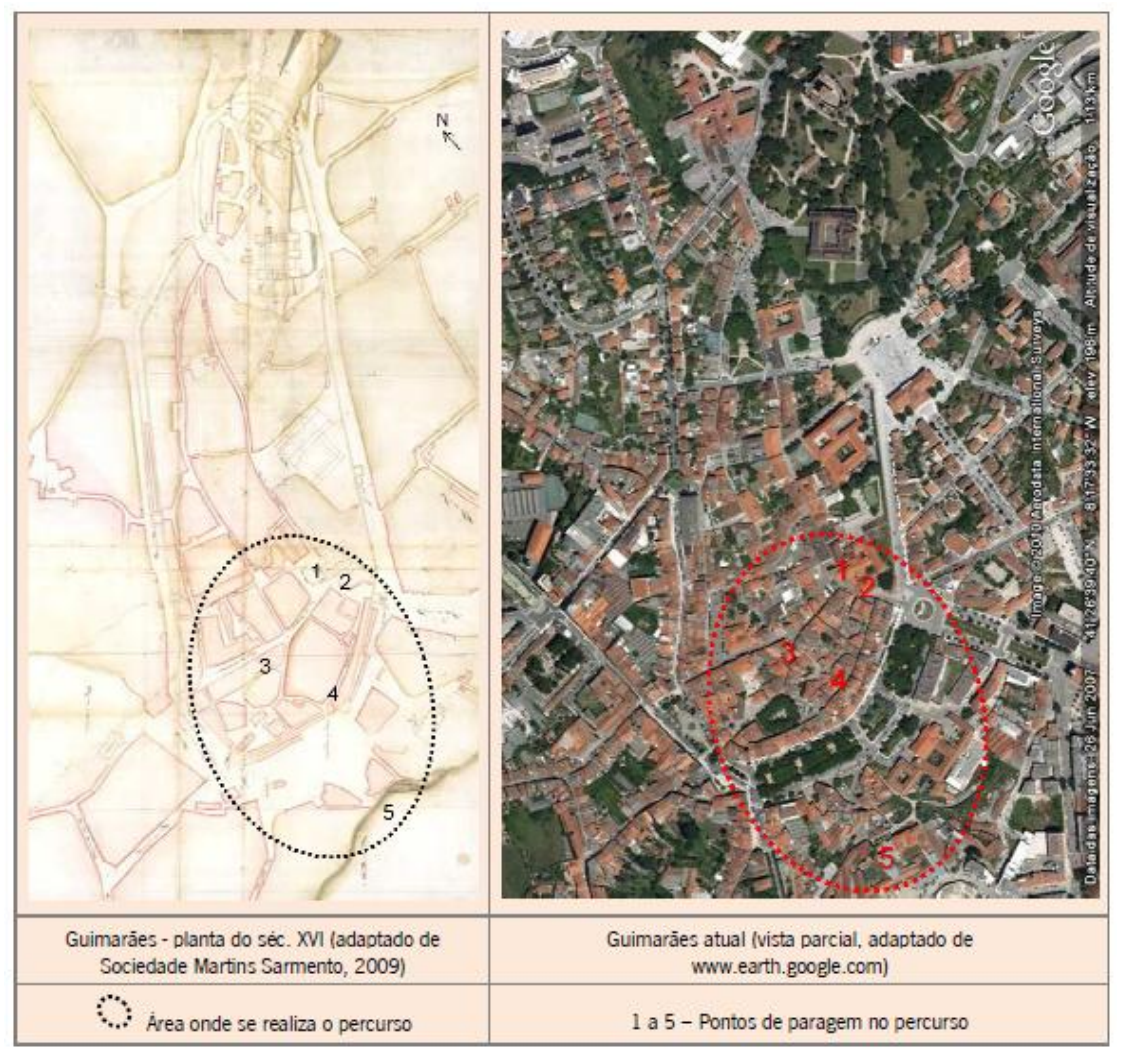

Figura 1 - Plantas de Guimarães no passado e no presente. 
O guião-questionário aplicado aos alunos integrou questões orientadoras, específicas e graduais - podendo ser agrupadas em categorias relacionadas com os materiais utilizados, as funções, símbolos de poder e a referência a mudanças ao longo do tempo. Procurou-se colocar tarefas que permitissem responder ao problema e questões de investigação, e que estivessem relacionadas com procedimentos cognitivos e o desenvolvimento de competências de aprendizagem em História, possibilitando aos alunos a compreensão da evidência histórica. Paralelamente pretendeu-se compreender os sentidos atribuídos pelos alunos às fontes patrimoniais (Figura 2), colocando questões que permitissem a articulação com conceitos ligados à consciência histórica, nomeadamente os de identidade e património.

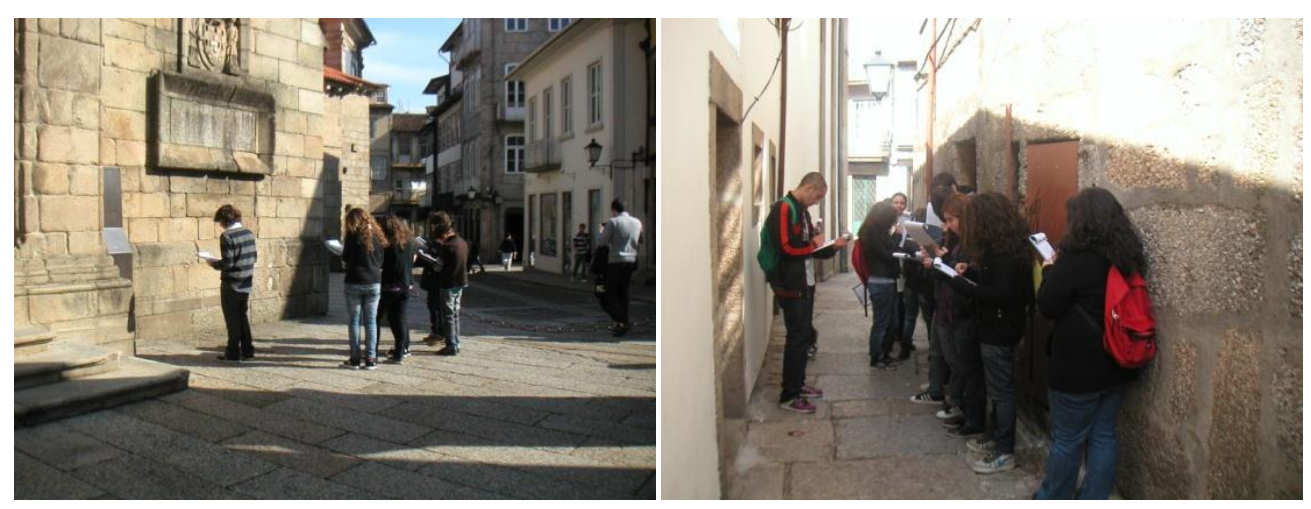

Figura 2 - Grupos de alunos de $7^{\circ}$ e de $10^{\circ}$ ano realizando atividade em diferentes pontos do percurso.

\section{Análise de dados}

Procedendo-se a uma análise qualitativa e indutiva dos dados das respostas de alunos e professores participantes no estudo empírico, a categorização dos dados foi progressivamente clarificada, aprofundada e sistematizada ao longo das fases exploratória, piloto e principal, no sentido de identificar perfis conceptuais e construir modelos consequentes de tarefas a aplicar em educação histórica e patrimonial.

A análise das respostas dos alunos ao guião-questionário estruturou-se em torno de dois construtos - "Uso da evidência" e "Consciência histórica" - 
e respetivas subcategorias, em termos de progressão conceptual, como se exemplifica a seguir.

\section{Uso da evidência}

Concepções de alunos relativamente ao modo como utilizam a informação e inferem a partir da leitura das fontes patrimoniais. Estas ideias são indiciadas quer nas respostas às questões em que se pedia uma afirmação, quer nas que apelavam à expressão de conjeturas.

\section{Alternativa}

Alguns alunos revelaram indefinição ou confusão na leitura que fizeram da fonte, ou inferiram com base em ideias de senso comum, extrapolando para a situação observada:

O que posso saber a partir daqui é que a pessoa que fez e pôs [a lápide] na igreja queria apresentar o seu trabalho para quem gosta de saber. (Alcina, 70 ano, 13 anos, Questão 1.1)

[O loudel] Parece uma espécie de robe, parece ser confortável. (Fausto, $10^{\circ}$ ano - HCA, 16 anos, Questão 2.2)

Inferência a partir de detalhes concretos

Descrição reportando informação a partir de elementos das fontes. Diversas respostas apresentaram uma descrição simples e outras, maior elaboração, onde veicularam apenas informação com base numa interpretação superficial. As conjeturas que vários alunos levantaram reportaram-se a detalhes factuais ou funcionais:

Foi um rei que mandou construir esta igreja. (Conceição, 70 ano, 12 anos, Questão 1.1)

Como é que este loudel foi encontrado? Onde? (Flora, 70 ano, 12 anos, Questão 2.4)

Não [tem a mesma função], pois no azulejo está escrito 'antiga albergariahospital'. Depois passou a ser albergue de S. Crispim - ceia do Natal. (Anabela, $10^{\circ}$ ano - HCA, 17 anos, Questão 3.1)

Porque é que tem "Ceia de Natal" escrito na tabuleta? (Marco, $10^{\circ}$ ano Hist.A, 15 anos, Questão 3.3)

Inferência a partir de elementos relacionados com o contexto

A contextualização é o ponto de partida para a consideração da evidência histórica. Um número expressivo de respostas revelou inferências 
pessoais com base em conhecimentos prévios, situando no tempo a informação genérica ou detalhada das fontes ou estabelecendo algum elo com o contexto político e social. As conjeturas levantadas por alguns alunos indiciaram preocupações temporais e sociais na interpretação das fontes patrimoniais:

Consigo observar que é uma peça de vestuário militar que parece ter sangue. (Fábio, 70 ano, 12 anos, Questão 2.2)

Este objeto [lápide] comparado com o outro é muito mais trabalhado, contém símbolos de Portugal interiorizados em flores ao lado, a margem é trabalhada na forma vegetalista, está escrita em forma gótica, a outra na forma do século 17. (Plácido, $10^{\circ}$ ano - HCA, 15 anos, Questão 2.1)

Era decorado dependendo da fortuna de cada um? (Silvana, $10^{\circ}$ ano - Hist.A, 16 anos, Questão 2.4)

Qual seria o espírito que os costureiros tinham no momento em que fizeram o loudel? (Vasco, 70 ano, 12 anos, Questão 2.4)

\section{Problematização}

Inferências pessoais problematizadoras, formulando questões sobre o contexto em termos de relações temporais, ou questionando a evidência (com base no cruzamento de elementos políticos, militares, sociais, económicos, de um mesmo contexto), ou colocando hipóteses à luz de possibilidades diversas (fazendo conjeturas sobre vários contextos em termos de relações temporais), como revelaram as respostas de um pequeno grupo de alunos:

O Albergue foi construído antes desta casa [da rua de Egas Moniz], mas dizse que esta casa é a casa mais antiga de Guimarães. Ganhou um prémio por essa causa. (Ivone, 70 ano, 12 anos, Questão 4)

Posso saber que é uma peça muito frágil, está rompida, mas eu acho que este poderá não ser o loudel de D. João I. (Patrício, 70 ano, 12 anos, Questão 2.2)

Que materiais hospitalares utilizavam neste hospital? Que necessidades passavam? Iam para a guerra ajudar os cavaleiros e o rei? (Alexandra, $10^{\circ}$ ano - Hist.A, 15 anos, Questão 3.3)

O que era para o povo daquela época uma igreja, pois se a construiu e não um centro comercial? Agora seria. (Isaura, 70 ano, 12 anos, Questão 1.3)

Relativamente ao modo como utilizam a informação e inferem a partir da 'leitura' das fontes patrimoniais, muitos alunos do 70 ano, mas também do $10^{\circ}$ ano, entenderam as fontes (escritas e patrimoniais) como 
provedoras diretas de informação. Nas suas respostas predominaram as descrições reportando informação a partir de alguns elementos das fontes e as conjeturas que levantaram reportaram-se sobretudo a detalhes factuais ou do quotidiano.

\section{Consciência histórica}

Concepções de alunos relativamente ao modo como dão sentido à relação dialógica entre passado e presente. Tipos de compreensão que os alunos revelaram acerca do significado do património no passado e no presente, a partir da 'leitura' das fontes patrimoniais, em termos de significância social - compreensão das ações humanas no passado - e de significância pessoal, nomeadamente de ideias acerca da relação passadopresente quanto a características sociais, económicas e culturais.

Consciência a-histórica

A um nível menos elaborado, algumas respostas não fazem alusão a qualquer tipo de significância ou apresentam ideias vagas ou estereótipos:

Transmitir uma mensagem, ou os seus pensamentos. Talvez não consigamos perceber o que eles queriam transmitir. (Adelina, 70 ano, 12 anos, Questão $1.2 \mathrm{a} / \mathrm{b})$

Interessante, bonita. Andamos muito. (Plínio, 70 ano, 13 anos, Questão 6)

Consciência de um passado fixo

As atitudes das pessoas do passado são avaliadas à luz de valores do presente. O passado, em termos genéricos, é visto como intemporal, como um conjunto de acontecimentos estáticos. Para um grupo numeroso de alunos, o passado é concebido à imagem do presente para simples conhecimento:

O loudel é feio e vê-se que é antiquado. (Tatiana, $10^{\circ}$ ano - Hist.A, 16 anos, Questão 2.3b)

Eram vidas interessantes, mas eram antigas. (Fábio, 70 ano, 12 anos, Questão 6)

É importante pois este monumento vai-nos transmitir a época e o significado desta batalha. (Eva, $10^{\circ}$ ano - Hist.A, 15 anos, Questão 1.2b)

Para ficar registado alguns momentos ou acontecimentos importantes. (Bianca, 70 ano, 13 anos, Questão 1.2a) 
Não vejo muitas referências que possamos identificar. Será preciso conhecer bem o local. (Vicente, $10^{\circ}$ ano - HCA, 15 anos, Questão 5.2b)

Consciência de um passado simbólico

A forma como o património chegou ao presente e a sua preservação são compreendidas em termos do seu significado como evocação de acontecimentos chave do passado (Rüsen, 2004; Seixas e Clark, 2004) ou pela sua simbologia em termos de identidade local e/ou nacional.

Diversas respostas indiciaram um uso do passado em relação com um presente emocionalmente simbólico; valorizam as fontes patrimoniais no passado e presente pelo seu simbolismo ou monumentalidade, revelando um sentido de identidade local:

Acho que influenciou porque o artesanato, a escultura, a arquitetura, etc... tem tudo a ver com o nosso passado maravilhoso, e acho que as pessoas olham sempre para o passado. (Irene, $7^{\circ}$ ano, 12 anos, Questão 6)

A vida em Guimarães nos séculos XIV-XV marcou muito os vimaranenses, influenciou muito na vida que levamos hoje. É uma cidade linda e única e todos os vimaranenses orgulham-se da sua cidade. Guimarães o berço de Portugal. (Joaquim, $10^{\circ}$ ano - HCA, 16 anos, Questão 6)

Um número expressivo de respostas, baseando-se na informação disponível em termos de significância social, reconheceu o património local como símbolo associado a um sentido de identidade nacional. Revelaram também uma conceção do passado como 'lição' ao referir-se aos antepassados como modelo para o presente:

Para entendermos o sacrifício dos nossos antepassados pela nossa nação. (Anabela, $10^{\circ}$ ano - HCA, 17 anos, Questão 2.3b)

Foi muito importante pois demonstraram a sua grande vitória na batalha. Eles quiseram que as gerações futuras soubessem que nós vencemos a batalha, 0 que é muito importante para nós hoje em dia. (Silvana, $10^{\circ}$ ano - Hist.A, 16 anos, Questão 1.2)

\section{Consciência histórica emergente}

A relação passado-presente é compreendida de forma linear quanto ao uso e função das fontes patrimoniais e características socioeconómicas associadas ao passado ou ao presente, embora se proceda à sua contextualização revelando uma orientação temporal emergente, como revelaram as respostas de diversos alunos: 
Saber como os guerreiros se vestiam naquela época. (Irina, 70 ano, 13 anos, Questão 2.3b)

Naquela época é normal ter construído este edifício por causa de muitas doenças como a Peste Negra. (Denise, $10^{\circ}$ ano - HCA, 17 anos, Questão 3.2b)

Era importante para os sapateiros pois eram cavidades onde se curtiam as peles para depois serem utilizadas para o trabalho destes. (Mara, $10^{\circ}$ ano HCA, 15 anos, Questão 5.2a)

Os métodos antigos ajudaram a desenvolver novas técnicas e a perceber como eram as suas vidas no passado. Os habitantes puderam também adquirir conhecimentos culturais sobre a vida em Guimarães. (Pascoal, 70 ano, 13 anos, Questão 6)

\section{Consciência histórica explícita}

Um número mais restrito de respostas revelou um sentido relacional entre passado, presente e futuro, utilizando noções de mudança e permanência como formas de conceptualizar as relações entre os fenómenos em diferentes momentos do tempo, e a interpretação das fontes patrimoniais tendo em consideração a diversidade dos contextos socioeconómico, político, cultural e sua articulação como essenciais à compreensão histórica:

A importância era terem peles para o comércio e abastecimento da capela e do albergue. Está tudo aqui relacionado. (Isaura, 70 ano, 12 anos, Questão $5.2 \mathrm{a} / \mathrm{b})$

Esta época foi marcada sobretudo pela religião, daí criarem-se igrejas em honra de feitos gloriosos de Portugal. (Adelaide, $10^{\circ}$ ano - Hist.A, 16 anos, Questão 1.2a)

Penso que na maioria das vezes não nos damos conta da história que a nossa cidade tem. Tantos aspetos que podem ser reconhecidos e aprofundados. Neste percurso vimos construções na cidade, como as casas, orgulho nas construções (lápide), atividades económicas que sempre caracterizaram a cidade e "simples" objetos de proteção. Várias coisas de que nos vamos apercebendo e que tornam esta cidade o que ela é, um centro de cultura para ser explorado por grande parte da população, se não por toda. (Luísa, $10^{\circ}$ ano - Hist.A, 15 anos, Questão 6)

Relativamente ao modo como dão sentido à relação dialógica entre passado e presente, a partir da 'leitura' das fontes patrimoniais, em termos de significância social e de significância pessoal, um grande número de alunos avaliou as atitudes das pessoas do passado à luz de valores do presente, ou entendeu o passado, em termos genéricos, como intemporal e, 
sobretudo, concebeu o passado à imagem do presente para simples conhecimento. No entanto, algumas respostas, sobretudo de alunos do $10^{\circ}$ ano, mostraram um sentido relacional entre passado, presente e hipóteses de futuro, revelando, ainda, uma consciência da historicidade das fontes patrimoniais, reconhecendo a sua interpretação de forma contextualizada como fundamental para a compreensão histórica e aplicando, por vezes, conceitos próprios da metodologia da História.

Simultaneamente considerou-se essencial compreender como os professores - mediadores entre as fontes históricas e a sua interpretação pelos alunos - tomam consciência da importância do uso das fontes patrimoniais como evidência, de acordo com critérios metodológicos da História.

Quanto às conceções de professores, também emergiu um modelo conceptual em torno de dois construtos: "Uso de fontes patrimoniais" e "Finalidades de ensino e divulgação do património", por sua vez organizado em três dimensões (Aprendizagem, Consciência Histórica e Consciência Patrimonial), cada uma delas envolvendo também padrões conceptuais específicos, como se exemplifica a seguir.

\section{Uso de fontes patrimoniais}

Modo como os professores procuram mediar a relação que os seus alunos estabelecem com os vestígios do passado em atividades de ensino e aprendizagem de História.

\section{Uso tácito}

Um número reduzido de respostas identificou genericamente atividades de exploração do património com os alunos, sem clarificar como se poderiam usar as fontes patrimoniais, ou salientando apenas resultados dessas atividades:

Pode ajudar a refletir sobre o património, preservar os nossos legados e participar ativamente na construção do Bem Comum. (Helga, prof. 70 ano, Questão 3 - questionário prévio) 


\section{Do contexto para a fonte}

Algumas respostas, principalmente no questionário prévio, revelaram sugestões de utilização de fontes patrimoniais em situação de exploração educativa, partindo do contexto exposto ou explicado (nos livros, na internet ou pelo professor) para o objeto, edifício ou local observado:

Pesquisa em livros e Internet de informação que permita interpretar e contextualizar as fontes históricas aqui apresentadas. (Heliana, prof. $10^{\circ}$ ano

- Hist.A, Questão 1 - questionário prévio)

\section{Cruzamento de fontes em contexto}

Diversas respostas, maioritariamente no questionário posterior, pareceram revelar o reconhecimento de que a observação orientada dos vestígios, relacionando fontes com linguagens diversas e aspetos políticoadministrativos, económicos e sociais em contexto, possibilita que os alunos interpretem as fontes patrimoniais como evidência histórica:

Esta atividade é essencial para o conhecimento histórico, dá a possibilidade ao aluno de conhecer e distinguir diferentes fontes de informação, interpretar documentos e formular hipóteses de interpretação de factos históricos (muito mais fácil numa aula de campo). (Heloísa, prof. 70 ano, Questão 1 questionário posterior)

O contacto com as fontes (observação in loco) e a sua contextualização permite aos alunos inferir sobre o contexto económico e social medieval. (Heliana, prof. $10^{\circ}$ ano - Hist.A, Questão 3 - questionário posterior)

Das fontes para o contexto

Outras respostas pareceram admitir que a abordagem multissensorial baseada no uso de fontes diversificadas suscita um diálogo histórico com significado para os alunos em relação ao passado. Um dos professores apontou possibilidades de inferência abdutiva, em que os alunos fazem conjeturas sobre as fontes com base nos conhecimentos que já possuem. Por sua vez, no questionário posterior à atividade, o mesmo professor apontou possibilidades de inferência indutiva, ao sugerir a análise de aspetos particulares dos vestígios, em termos de evidência histórica, para os alunos tirarem conclusões acerca do seu contexto, a nível económico, social, político:

Partindo do princípio que a vitalidade urbana e o desenvolvimento económico das mesmas promovem as manifestações artísticas. (Henrique, prof. $10^{\circ}$ ano - HCA, Questão 3 - questionário prévio) 
É uma atividade que se relaciona na perfeição com o currículo da disciplina pois permite a visualização do entorno artístico da cidade, permitindo ainda partir dos vestígios arquitetónicos para uma caracterização da economia, sociedade, política e mentalidade que concretizou os mesmos. (Henrique, prof. $10^{\circ}$ ano - HCA, Questão 1 - questionário posterior)

\section{Finalidades de ensino e divulgação do património}

Conceções de professores relativas ao modo como perspetivam o contributo da exploração de fontes patrimoniais na aprendizagem de História pelos alunos. Tipos de consciência que revelam em relação a esse processo de desenvolvimento do pensamento histórico dos alunos e às ligações que estes podem estabelecer entre identidade e património em termos de orientação temporal.

a) Aprendizagem

Os professores revelaram conceções diversas relativamente ao contributo do contacto direto com fontes patrimoniais e sua exploração no ensino de História, com vista ao desenvolvimento da aprendizagem dos alunos.

Motivação - algumas respostas salientaram a motivação que o contacto direto com o património histórico local pode proporcionar à aprendizagem dos alunos, parecendo implícita a ideia de que os alunos podem ver o passado como algo próximo da sua experiência quotidiana, não tanto em termos presentistas, mas como ponto de partida para a aprendizagem acerca do passado:

A História local, é uma variante estratégica e motivacional de ensino, é uma forma de despoletar o sentido da realidade histórica. (Heloísa, prof. $10^{\circ}$ ano HCA, Questão 2 - questionário posterior)

Consolidação de conhecimento - algumas respostas, sobretudo no questionário prévio, admitiram explicitamente a motivação e a consolidação de conhecimento como o principal objetivo do contacto com as fontes patrimoniais:

Proporcionar atividades diferentes que promovam o gosto e o contacto com museus e bibliotecas. Ao nível do 70 ano, complementa e ajuda na compreensão do programa curricular. (Helga, prof. 70 ano, Questão 1 questionário posterior)

Construção de conhecimento - noutras respostas pareceu claro que o papel do professor deve ser o de proporcionar aos alunos a orientação 
necessária para que estes interpretem as fontes patrimoniais por meio da inferência histórica. Desta forma a compreensão histórica dos alunos pode tornar-se ainda mais sofisticada:

Esta é (foi) uma atividade pertinente que coloca no aluno a responsabilidade de construir um raciocínio e uma discussão coerente sobre o período medieval. (Hugo, prof. $10^{\circ}$ ano - Hist.A, Questão 3 - questionário posterior)

\section{b) Consciência histórica}

Os professores revelaram tipos de consciência diversos relativamente ao processo de desenvolvimento do pensamento histórico dos alunos em termos de dinâmica de orientação temporal - passado, presente e, eventualmente, futuro - possibilitada pela interpretação de fontes patrimoniais.

Informação - algumas respostas revelaram ideias generalistas, assumindo como 'natural' o desenvolvimento do pensamento histórico dos alunos como resultado de uma atividade de contacto com o património mediada pelo professor:

Sendo uma atividade orientada pelo professor da disciplina, é lógico que os alunos vão inferir mais conhecimentos sobre o contexto económico e social medieval. (Heloísa, prof. 70 ano, Questão 3 - questionário prévio)

Conhecimento em contexto - diversas respostas reconheceram a possibilidade de uma compreensão contextualizada do passado através da interpretação das fontes patrimoniais:

O património observado permite aos alunos recolher informação sobre as atividades praticadas numa determinada região e, consequentemente, conhecer as condições de vida dos habitantes (as casas que habitavam e os materiais de que eram feitas, os objetos de adorno e o mobiliário, etc.). (Hermínia, prof. 70 ano, Questão 3 - questionário posterior)

Relação de tempos em mudança - algumas respostas indiciaram uma consciência da historicidade das fontes patrimoniais cuja interpretação ajuda compreender a complexidade da relação passado-presente num contexto amplo, reconhecendo a diversidade na mudança:

Conhecer melhor o passado/presente da cidade que habitam ou onde nasceram: toponímia, história dos monumentos, relação da História Local com a História Nacional. (Heliana, prof. $10^{\circ}$ ano - Hist.A, Questão 2 - questionário posterior) 


\section{c) Consciência patrimonial}

Os professores revelaram tipos de consciência diversos relativamente às formas como os alunos poderão orientar a sua vida prática, baseando-se na relação entre identidade e património que os alunos estabelecem ao interpretarem fontes patrimoniais.

Ideia difusa - um professor salientou o respeito pelo património, pelas 'marcas do passado', através de objetos específicos que podem 'evocar' o passado e devem ser preservados para uso no presente, o que parece implicar o comprometimento com uma determinada identidade coletiva que condiciona o indivíduo aos seus ancestrais:

Além do conhecimento histórico, o respeito pelas fontes históricas e pelo país, região, cidade que alberga essas fontes. (Helga, prof. 70 ano, Questão 2 questionário prévio)

Sentido de identidade local - algumas respostas realçaram o facto de as atividades de observação direta de fontes patrimoniais estimularem o sentimento de pertença a uma comunidade e a sensibilização para a preservação do património local, considerando que este materializa a identidade da comunidade, como depositário de casos 'exemplares' relevantes para a resolução dos problemas do presente, considerando, por vezes, que aquele seria ignorado pelos alunos:

Essencialmente viram um espaço que parecia que conheciam, com um outro olhar, observaram coisas pela primeira vez. Aprenderam a ver/observar com outra atenção, o que Ihes provocou maior curiosidade e interesse para a História Local e o seu Património, o qual muitas vezes lhes era indiferente. (Heloísa, prof. 70 ano, Questão 2 - questionário posterior)

Sentido de identidades múltiplas - um número menos expressivo de respostas pareceu revelar a consciência de que é possível ensinar a partir da observação do local para um quadro interidentitário:

Conhecer melhor o passado/presente da cidade onde habitam ou nasceram [...], relação da História Local com a História Nacional. (Heliana, prof. $10^{\circ}$ ano - Hist.A, Questão 2 - questionário posterior)

Construção de uma memória coletiva (histórica) comum de âmbito local (suscetível de ser alargada a um contexto nacional e europeu); sobre a complexidade da construção da "verdade histórica"; a pertinência de saber "olhar" criticamente para os vestígios materiais; integrar e relacionar conhecimentos adquiridos. (Hugo, prof. $10^{\circ}$ ano - Hist.A, Questão 2 questionário posterior) 
Assim, e relativamente aos professores, constatou-se, quanto ao uso de fontes patrimoniais, uma predominância do padrão conceptual "cruzamento de fontes em contexto"; em termos de finalidades de ensino e divulgação do património, na dimensão Aprendizagem predominaram os padrões "consolidação do conhecimento" e "construção do conhecimento", na dimensão Consciência Histórica destacou-se o padrão "conhecimento em contexto" e na dimensão Consciência Patrimonial, o padrão "sentido de identidade local".

\section{Considerações finais}

Foi no âmbito da educação histórica e patrimonial de alunos portugueses do $3^{\circ}$ ciclo do ensino básico e do ensino secundário, que se inseriu o estudo empírico desta investigação, no sentido de estimular nos alunos a capacidade de 'ler' objetos, edifícios e sítios históricos a nível local, familiarizando-os com o seu uso como evidência histórica. Considerando que a exploração educativa do património, de forma sistemática e fundamentada, poderá permitir o desenvolvimento do pensamento histórico e a aquisição de múltiplas competências pelos alunos (nomeadamente no âmbito da compreensão histórica), e dada a insuficiente investigação existente sobre o uso de fontes patrimoniais e sua interpretação em termos de evidência histórica no ensino e aprendizagem da História, este estudo pretendeu chamar a atenção para as implicações dessas atividades assim como a importância de os alunos efetuarem inferências com maior complexidade.

Na investigação que realizámos, ao longo do percurso e à medida que avançavam nas tarefas, estes alunos mostraram ganhar progressivamente mais confiança em lidar com as fontes como evidência, interpretando-as em contexto a partir de um quadro analítico: descrição de mudanças, questionamento, formulação de conjeturas. Revelaram inferências pessoais, procedendo a uma contextualização da informação em termos sociais, culturais, políticos e económicos, relacionando-a com os seus 
conhecimentos prévios. Assim, diversos alunos do $7 .^{\circ}$ ano e um pouco mais do $10^{\circ}$ ano, para além de descreverem o que observavam, inferiram a partir de detalhes arquitetónicos, escultóricos, de vestuário ou de estruturas, sobre o contexto económico, social e cultural - por exemplo, alguns deles utilizaram termos referentes ao estatuto social que associaram aos objetos ou estruturas observados.

Alguns alunos de ambos os anos de escolaridade questionaram a 'verdade' transmitida, levantaram questões acerca da credibilidade ou do estatuto da informação proporcionada, nomeadamente em relação ao 'loudel' exposto no Museu de Alberto Sampaio, indiciando entender a construção do conhecimento histórico a partir da interpretação crítica das fontes, ou seja, em termos de evidência histórica. Pareceram compreender a interação entre o passado e as representações físicas da História, não se limitando ao uso das fontes como informação ou materialização do passado, mas reconhecendo que elas devem ser interpretadas em contexto, tendo consciência da sua historicidade.

Neste estudo, o modelo conceptual de progressão por níveis de elaboração, ao permitir conhecer os modos como os alunos exprimem a sua compreensão do passado inferindo a partir de fontes patrimoniais e como tomam consciência da sua orientação temporal (menos ou mais fundamentada historicamente), pode contribuir para uma maior reflexão sobre as formas como os professores podem implementar abordagens melhor sustentadas do processo de ensino e aprendizagem. É possível, através da seleção de tópicos relacionados com a história local, por exemplo, introduzir de forma interessante e adequada ao currículo a abordagem da educação patrimonial no âmbito da disciplina de História, recorrendo a um museu ou a um sítio histórico na área da escola. Por outro lado, o uso de fontes patrimoniais em tarefas metodologicamente adequadas pode facilitar a compreensão de conceitos históricos mais abstratos pelos alunos. Além disso, ao considerarem a evidência na interpretação de elementos reveladores de determinados contextos históricos, os alunos compreendem que as funções dos objetos e dos 
edifícios ou a organização urbana podem mudar ao longo do tempo e reconhecem a sua relação com o presente.

Para que os alunos progridam em termos de interpretação histórica, eles devem ser ajudados a considerar o contexto no qual os objetos e sítios históricos que observam foram produzidos e utilizados, e a discutir as suas perspetivas com os outros. Em termos de inferência, os alunos de 70 ano, participantes neste estudo, questionaram as fontes, problematizaram mais do que os de $10^{\circ}$ ano. Há condições para que os professores, com formação específica, possam desenvolver abordagens construtivas, elaborando propostas de tarefas quer para alunos do 30 ciclo quer para os do ensino secundário, proporcionando não só o cruzamento de fontes diversas (escritas, iconográficas, patrimoniais) em contexto, mas também partindo dessas fontes para os vários contextos, pondo em prática procedimentos de metodologia da História, mesmo em articulação com instituições de educação não formal.

Embora a maioria das situações de ensino tenham lugar na sala de aula, algumas, talvez até mais produtivas em termos da aprendizagem dos alunos, realizam-se no exterior, em sítios históricos, museus e, mesmo, no meio envolvente da escola. Reconhecer este potencial é também desafiador para a investigação em Educação Histórica, pois implica que se desenvolvam estudos que atendam à forma como os alunos aprendem em diferentes contextos e ao tipo de abordagem mais adequada para desenvolver, por exemplo, a 'leitura' de vestígios arqueológicos, edifícios ou objetos de museus, ou narrativas de história oral - sem perder de vista a sua inserção num processo. Assim será possível ultrapassar uma visão impressionista de experiência meramente lúdica de saída do espaço escolar e reconhecer o seu papel no desenvolvimento da compreensão da evidência pelos alunos, envolvendo-os na construção do seu conhecimento histórico. 


\section{Referências}

ANGVIK, M.; BORRIES B. (Eds.). Youth and History: a comparative European survey on historical consciousness and political attitudes among adolescents, vols. A and B. Hamburg: Körber-Stiftung, 1997.

ASHBY, R. O conceito de evidência histórica: exigências curriculares e concepções dos alunos. In BARCA, I. (Org.). Educação Histórica e Museus. Actas das Segundas Jornadas Internacionais de Educação Histórica. Braga: CIEd, Universidade do Minho, 2003, p. 37-57.

. Desenvolvendo um conceito de evidência. Educar em revista, número especial, 2006, p. 151-170.

ASHBY, R.; LEE, P.; SHEMILT, D. Putting principles into practice: teaching and planning. In DONOVAN, M. S.; BRANSFORD, J. D. (Eds.), How students learn: History in the classroom. Washington DC: The National Academies Press, 2005, p. 79-178.

BARCA, I. Estudos de Consciência Histórica em Portugal: perspectivas de jovens portugueses acerca da História. In BARCA, I. (Org.). Estudos de Consciência Histórica na Europa, América, Ásia e África. Actas das Sétimas Jornadas Internacionais de Educação Histórica. Braga: CIEd, Universidade do Minho, 2008, p.47-53.

CAINELLI, M. Educação Histórica: perspectivas de aprendizagem da história no ensino fundamental. Educar em revista, número especial, Curitiba: Editora UFPR, p. 57-72, 2006.

CHAPMAN, A. Asses, archers and assumptions: strategies for improving thinking skills in history in years 9 to 13. Teaching History, 123, p. 6-13, 2006.

CHOAY, F. A Alegoria do Património. Lisboa: Edições 70, 2000.

COLLINGWOOD, R. The idea of History. Oxford: Oxford University Press, 1946.

A ideia de História. 9 ed. Lisboa: Editorial Presença, 2001.

COOPER, H. O pensamento histórico das crianças. In BARCA, I. (Org.). Para uma Educação Histórica de qualidade. Actas das Quartas Jornadas Internacionais de Educação Histórica. Braga: CIEd, Universidade do Minho, 2004, p. 55-74.

- Aprendendo e ensinando sobre o passado a crianças de três a oito anos. Educar em revista, número especial, 2006, p. 171-190.

DICKINSON, A. K.; GARD A.; LEE, P. J. Evidence in history and the classroom. In DICKINSON, A.; LEE P. (Eds.), History teaching and historical understanding. London: Heinemann, 1978, p. 1-20.

LEE, P. 'Walking backwards into Tomorrow': historical consciousness and understanding History, 2002. Consultado em Março 7, 2011, em http://www.cshc.ubc.ca. 
- Nós fabricamos carros e eles tinham que andar a pé: compreensão da vida no passado. In BARCA, I. (Org.). Educação Histórica e Museus. Actas das Segundas Jornadas Internacionais de Educação Histórica. Braga: CIEd, Universidade do Minho, 2003, p. 19-36.

Putting principles into practice: understanding history. In DONOVAN, M. S; BRANSFORD, J. D. (Eds.), How students learn: history in the classroom. Washington, DC: The National Academies Press, 2005, p. 31-77.

LEVSTIK, L.; HENDERSON, A.; SCHLARB, J. Digging for clues: an archaeological exploration of historical cognition. In ASHBY, R.; GORDON, P.; LEE, P. (Eds.), Understanding history: recent research in History Education. London: Routledge Falmer, 2005, p. 37-53.

LOWENTHAL, D. The past is a foreign country. Cambridge: C. University Press. 1999.

LYNCH, K. What time is this place? Cambridge, Massachusetts: The MIT Press, 1998.

MCCULLAGH, C. B. The truth of history. London: Routledge, 1998.

NAKOU, I. Exploração do pensamento histórico das crianças em ambiente de museu. In BARCA, I. (Org.). Educação Histórica e Museus. Actas das Segundas Jornadas Internacionais de Educação Histórica. Braga: CIEd, Universidade do Minho, 2003, p. 59-82.

NAKOU, I. Museums and History Education in Our Contemporary Context. International Journal of Historical Learning, Teaching and Research, 6(1), 2006. Acesso em 29 de abril de 2012, http://www.centres.ex.ac.uk/historyresource/journalstart.htm.

PAIS, J. M. Consciência histórica e identidade: os jovens portugueses num contexto europeu. Oeiras: Celta Editora, 1999.

PINTO, H. O triângulo Património-Museu-Escola: que relação com a Educação Histórica? In SCHMIDT, M. A.; BARCA, I. (Org.). Aprender História: Perspectivas da Educação Histórica. Ijuí: Ed. Unijuí, 2009, p. 271302.

A melhor forma de conhecer a história de Guimarães é ir explorar': compreensão histórica de alunos portugueses sobre evidência patrimonial. In SCHMIDT, M. A.; CAINELLI, M. (Org.). Educação Histórica: Teoria e Pesquisa. Ijuí: Ed. Unijuí, 2011a, p. 167-192.

PINTO, H. Educação histórica e patrimonial: conceções de alunos e professores sobre o passado em espaços do presente. Tese de doutoramento em Ciências da Educação, especialidade de Educação em História e Ciências Sociais, apresentada à Universidade do Minho, 2011b.

PINTO, H; BARCA, I. "Leitura" de fontes patrimoniais como evidência histórica: perspetivas de alunos. In BARCA, I. (Org.). Educação e Consciência Histórica na Era da Globalização. Braga: CIEd, Instituto de Educação, Universidade do Minho, Associação de Professores de História, 2011, p. 79-96. 
- Uso de fontes patrimoniais e consciência histórica de alunos e professores portugueses. XII Congresso Internacional das Jornadas de Educação Histórica Consciência Histórica e as novas tecnologias da informação e comunicação. Universidade Federal do Paraná, Curitiba, 18-21 de julho de 2012.

RAMOS, F. R. A danação do objecto: o museu no ensino de história. Chapecó: Argos, 2004.

RÜSEN, J. Razão histórica. Teoria da História: os fundamentos da ciência histórica. Brasília: Editora UnB, 2001a.

. What is Historical Consciousness? A theoretical approach to empirical evidence. Centre for the study of Historical Consciousness, University of British Columbia Vancouver, 2001b. Consultado em abril 29, 2012, em http://www.cshc.ubc.ca.

Historical Consciousness: narrative structure, moral function, and ontogenetic development. In SEIXAS, P. (Ed.), Theorizing Historical Consciousness. Toronto: University of Toronto Press, 2004, p. 63-85.

SCHMIDT, M. A.; GARCIA, T. B. O trabalho com objetos e as possibilidades de superação do sequestro da cognição histórica: estudo de caso com crianças nas séries iniciais. In SCHMIDT, M. A.; GARCIA, T. B. (Org.). Perspectivas de Investigação em Educação Histórica. Curitiba: UFPR, 2007, p. 52-57.

SEIXAS, P.; CLARK, P. Murals as monuments: students' ideas about depictions of civilization in British Columbia. American Journal of Education, 110(2), 2004, p. 146-171.

SHEMILT, D. History 13-16: Evaluation Study. Schools Council History 1316 Project. Edinburgh: Holmes McDougall, 1980.

SIMÃO, A. C. A construção da evidência histórica: concepções de alunos do 3. ${ }^{\circ}$ ciclo do ensino básico e secundário. Tese de doutoramento em Educação - Metodologia do Ensino de História e Ciências Sociais, Universidade do Minho, Braga, Portugal, 2007.

SOLÉ, M. G. A História no $1^{\circ}$ Ciclo do Ensino Básico: a concepção do tempo e a compreensão histórica das crianças e os contextos para o seu desenvolvimento. Tese de doutoramento em Estudos da Criança - Estudo do Meio Social, Universidade do Minho, Braga, 2009.

STRAUSS, A.; CORBIN, J. Basics of qualitative research: techniques and procedures for developing Grounded Theory. Thousand Oaks: Sage, 1998.

YÁNEZ CASAL, A. Património e modernidade. In Museologia e Autarquias: Actas do IV Encontro Nacional. Tondela: Câmara Municipal de Tondela, 1999, p. 57-61. 